\title{
Active Decisions and Pro-Social Behavior
}

\author{
Alois Stutzer, Lorenz Goette, and Michael Zehnder
}

\begin{abstract}
:
In this paper, we propose a decision framework where people are individually asked to either actively consent to or dissent from some pro-social behavior. We hypothesize that confronting individuals with the choice of whether to engage in a specific pro-social behavior contributes to the formation of issue-specific altruistic preferences, while simultaneously involving a commitment. The hypothesis is tested in a large-scale field experiment on blood donations. We find that this "active-decision" intervention substantially increases the actual donation behavior of people who had not fully formed preferences beforehand.
\end{abstract}

\section{JEL Classifications: C93, D64, I18}

Alois Stutzer is an assistant professor at the University of Basel. Lorenz Goette is a senior economist at the Federal Reserve Bank of Boston's Research Center for Behavioral Economics and Decision-Making. Michael Zehnder is a graduate student at the University of Basel. Their email addresses are alois.stutzer@unibas.ch, lorenz.goette@bos.frb.org, and michael.zehnder@unibas.ch, respectively.

This paper, which may be revised, is available on the web site of the Federal Reserve Bank of Boston at http://www.bos.frb.org/economic/wp/index.htm.

The views expressed in this paper are those of the authors and do not necessarily represent the views of the Federal Reserve Bank of Boston or the Federal Reserve System.

We are grateful to James Andreoni, Christine Benesch, Matthias Benz, Bruno Frey, Gilad Hirschberger, Dean Karlen, Simon Lüchinger, Susanne Neckermann, and the participants of the American Economic Association Meeting, the Conference on Behavioral Approaches to Legal Compliance in Jerusalem, the Meeting of the Swiss Society of Economics and Statistics, the Behavioral Public Economics Workshop in Coopenhagen, the CASBS reunion in Berkeley, and seminars in Basel and Munich for helpful comments. We wish to thank the Stiftung Zürcher Blutspendedienst SRK, especially Beat Frey, Heinz Jehle, and Gertrud Stäheli, for their support of the project. Goette thanks the SNF for financial support under grant no. 101312-103898/1. This paper is part of the Research Priority Program of the University of Zurich on "The Foundations of Human Social Behavior: Altruism versus Egoism."

This version: June 11, 2007 
One of the greatest challenges to institutional choice is the design and implementation of decision-making mechanisms that promote pro-social behavior. Alfred Marshall noted in 1890 that "[n]o doubt men, even now, are capable of much more unselfish service than they generally render: And the supreme aim of the economist is to discover how this latent social asset can be developed most quickly, and turned to account most wisely."

In this paper, we propose and study empirically a decision framework where people are individually asked to either actively consent to or dissent from some pro-social behavior. This is in stark contrast to some noncommittal appeals to behave pro-socially that address everybody in the same way. Consider, for example, the issue of blood donations. With an active decision, people are confronted with a request to donate blood, to which they are expected to respond with either a "yes" or a "no." It is argued that an active decision induces people to deal with a specific pro-social behavior and makes them aware of the social value of that particular behavior. By doing so, an active decision contributes to the formation of issue-specific altruistic preferences, while simultaneously involving a commitment. We thus understand active decisions as an elicitation mechanism, as mentioned by Marshall, capable of transforming a latent willingness to donate, contribute, or share into actual pro-social behavior. ${ }^{1}$ This is our basic hypothesis.

The hypothesis rests on insights in economics and psychology that preferences are partly formed in the process of decision-making in unfamiliar choice situations. A pertinent example is the creation of non-use values in contingent valuation studies (Kahneman, Ritov, and Schkade, 1999). In active decisions, people are made aware of some particular issue and are induced to engage in cognitive evaluation and reasoning (see, for example, Cioffi and Garner (1996)). In blood and post-mortem organ-donation decisions, the deliberation involves dealing with one's own health, and people are motivated to get over the denial and repression of their own mortality.

The behavioral consequences of confronting people with the decision whether to act pro-socially may not be uniform, but may depend on the degree of stability of the subjects' altruistic preferences with regard to a specific issue. The effect of active decisions on behavior, by its very nature, relies on the endogenous formation of preferences inherent in the process. We therefore expect that active

\footnotetext{
${ }^{1}$ Active decision-making might also be relevant in overcoming self-control problems. Choi et al. (2004) study the effect of active decision-making on the likelihood of joining a pension savings plan.
} 
decisions will be more effective in influencing preference formation when people are unaware of the importance of a specific pro-social engagement, and when their latent motivation to donate or contribute would otherwise remain dormant. We refer to effect of this distinction (between being aware and being unaware of the importance of the pro-social engagement) as the differentiated hypothesis.

In contrast, if people are well aware of a public good and have already made up their minds about their contributions to it, preferences can be expected to be rather stable and little affected by active decisions. If these same (aware) people are confronted with an active-decision mechanism, they may actually perceive the intervention as intrusive and even reduce their contribution (see Frey (1997) for a general account of the crowding-out effect in contributions to public goods).

We study the potential of active decisions to motivate voluntary blood donations. The steady tightening of access criteria for blood donors increases the risk of excess demand for blood. It is still technically impossible to reproduce blood compounds artificially. If new donors are not successfully recruited on a regular basis, blood shortages may become a central health care problem. ${ }^{2}$ Moreover, there is evidence that many latent donors have never contemplated becoming active donors (Lemmens et al., 2005). We thus hypothesize that an active-decision framework can successfully elicit blood donations.

Our study was incorporated in a Red Cross blood drive at the University of Zurich. In total, more than 1,800 students participated. They knew neither that an experiment was taking place nor that researchers from the economics department were involved. Professors granted us permission to distribute a brief survey during the last 10 minutes before the break in the middle of their lectures, and to make a brief announcement regarding the blood drive. We implemented three experimental conditions - two involving active decisions in which people had to report a preference and a third, control condition. In the "strong active decision" treatment, the survey contained a page at the end asking the subjects whether they were willing to donate blood at one of the times mentioned on the information sheet. They had two possible choices: "yes" or "no." If they answered "yes," they had to say when they would show up for the blood donation. In the "weak active decision" treatment, the last page of the survey was nearly identical; we merely added a third possible option, allowing

\footnotetext{
${ }^{2}$ We emphasize voluntary blood donation because no accepted alternative social arrangement for activating people to donate blood seems to exist. In particular, a majority rejects the installation of a market, and markets of this type have not performed well in the past (for a discussion, see Titmuss (1972)).
} 
them to state that they did not want to make a decision. In a control condition, there was no such page at the end of the survey. However, along with the survey, all students also received an information sheet, listing dates and times in the week when they could come to donate blood. To obtain a measure of the latency of pro-social preferences, we asked the students in the survey whether they felt they were sufficiently informed about the importance of donating blood.

Our results lend support to the hypothesis that active decisions play an important role in uncovering latent pro-social preferences. We find that among students who indicated that they were not sufficiently aware about the importance of donating blood, the strong active decision treatment increased blood donations in the following week significantly relative to the control condition. Confronting this group of subjects with explicit choice options thus increased participation. This result also holds when we control for previous blood donations. Hence, the result is not due to experimentation to find out what the experience of donating blood is like. In contrast, we even find a slightly negative effect (albeit not statistically significant) of the strong active decision treatment on blood donation for the group of students who stated that they are sufficiently aware of the importance of donating blood. Overall, we interpret the results as evidence that active decisions can help to develop Marshall's latent social asset.

The remainder of the paper is structured as follows: Section I describes the experimental design in detail. Section II provides descriptive statistics, and Section III presents the results of the experiment. Section IV offers concluding remarks.

\section{Experimental Setup}

We conducted our experimental study in the context of a regular blood drive that the Swiss Red Cross (SRC) arranges at the University of Zurich. In a normal year, the SRC simply posts informational material in classrooms, listing the hours and location of the blood drive. In our case, the Swiss Red Cross, in collaboration with us, obtained permission to conduct a study in seven large undergraduate lectures at the University of Zurich.

The study consisted of a six page survey, which contained demographics, questions aimed at measuring pro-social preferences, and personality scales. The survey also contained several questions regarding donating blood. Our key question that captures the underlying concept of preference formation refers to the subjects' awareness of the importance of donating blood. It reads, "Do you 
feel sufficiently informed about the importance of donating blood?" and had to be answered with a "yes" or a "no." The parameter value "yes" is labeled "aware;" "no" is labeled "not aware." The question avoids asking specifically about topic-related knowledge. However, individuals answering "no" have arguably given less thought to the matter, without implying a preference in either direction.

\section{A. Treatments}

There were three experimental conditions manipulating active decision-making. In all three treatments, subjects received a separate, general information sheet listing the times and places of the blood drive. In bold letters it said, "FOR YOU TO TAKE HOME." The three treatments differed as follows:

Strong $A D$ : For the subjects in this treatment, the last page of the survey contained a sheet inviting them to donate blood. It also listed the times and places of the blood drive and, most importantly, asked individuals to either agree or refuse to participate in the blood drive by checking a "yes" or a "no" box. If a subject chose to participate, he or she was asked to commit to an actual date and time for the blood donation. Subjects also received the general information sheet about the blood drive, mentioned above.

Weak $A D$ : The last sheet for this group was almost identical to that of the group with a strong $A D$. The only difference was that it contained an additional box, saying, "I do not want to make a decision" [about donating blood]; that is, no decision was required. Again, subjects also received the general information sheet to take home.

No $A D$ : The survey in the third treatment did not contain a page asking for an explicit choice. Like everybody else, however, the subjects received a sheet containing identical general information about the blood drive.

\section{B. Procedures}

In order to implement the treatments in a large population, we selected seven large lectures and asked the professors to concede 10 minutes of their lectures before the break. A representative of the SRC gave a brief informational presentation, while the assistants distributed the survey. There is no reason to believe that the students were aware that an experiment was being conducted.

We decided how to distribute the different treatments in the lecture rooms based on their layout plans. To ensure that students would not notice that 
an experiment was being conducted, we used natural barriers, such as aisles, to separate the sections where the different treatments were distributed. The assignment of the treatments to the various treatment sections was random. Depending on the layout of the lecture room, it was sometimes impossible to conduct all three treatments. Therefore, treatments were randomized within lectures, but not across them (see Table 8 for the distribution of observations across treatments and lectures).

Special care was taken to ensure identical information conditions for all subjects. After the students had worked on the survey for about 5 minutes, the assistants distributed the additional information sheet that contained the same information (and the same invitation, word for word) as the last page of the survey for the two groups facing $A D$. This was done to make sure that all students had the same information not only regarding the times and places of the blood drive, but also regarding the normative value of the campaign. We printed the extra sheet on colored paper to ensure that the students would notice it. Furthermore, the times and places of the blood drive were also mentioned during the SRC representative's presentation. After 10 to 15 minutes, the subjects left the lecture room to take a break and handed in the questionnaires to the support staff at the exit doors.

\section{Descriptive Statistics}

Participation in the study was high; the response rate was well above 95 percent. ${ }^{3}$ In total, 1,852 questionnaires were handed in. Four people were younger than 18 and thus not allowed to donate blood. Another 10 people did not answer the question regarding awareness of the importance of donating blood. It was possible to match all the blood donations to one of the remaining 1,838 subjects. $^{4}$

Table 1 provides a first impression of the data. It shows the stated willingness to donate blood, the share of individuals actually donating blood in the blood drive, and the answers to the question regarding awareness of the importance of donating blood. Fourteen percent of the respondents indicate a willingness to donate blood in the survey. This share is calculated based on

\footnotetext{
${ }^{3}$ Only a few people were observed leaving the lecture halls without handing in a questionnaire.

${ }^{4}$ Subjects were offered participation in a raffle if they provided their address at the end of the questionnaire. In parallel, all the donors in the blood drive were asked whether they had participated in the survey study. We successfully linked to the questionnaires of all donors who reported participating in the study.
} 
the stated preferences of the subjects in the two $A D$ treatments. Of the sample population, 7.6 percent actually donated blood. The table shows that donations differ considerably among the various courses covered. First and second-year medical students have by far the highest propensity to donate blood, followed by biology students. It is difficult to interpret any difference in donation behavior across courses, as they may reflect differences in preferences, work load, study schedule, etc. There are also differences in answers to the awareness question between courses. While almost 90 percent of the second-year medical students answer that they feel sufficiently informed about the importance of donating blood, only slightly more than half of the students in the journalism course say so.

Before reporting the results of the experiment, we performed tests to verify the randomization. We ran regressions of several measures that could influence blood donations on a set of class fixed effects and indicator variables for our treatment conditions. If randomization worked, then there should be no differences in the measures between the different treatment conditions (recall that we only randomized within a class).

The measures we consider in this test are measures that previous evidence suggests may be correlated with blood donations. Specifically, we test for differences in previous donations, whether the subjects felt sufficiently informed about the importance of blood donations, differences in three psychological traits that may be related to blood donations (openness to new experiences, extroversion, and conscientiousness), gender, and age. Given our sample size, we should be able to detect differences among groups if the differences in the measures exceed approximately 5 percent of the mean.

Table 2 reports the regression coefficients for the weak $A D$ and strong $A D$ conditions (the control condition is the reference category), and the $p$-values of a joint test that the treatment conditions affect the outcome measures. As can be seen in Table 2, there is only one slight difference, in age, between the treatment conditions, but even this difference is quantitatively small. None of the other measures differ by treatment, not even at the liberal significance level of 10 percent.

Since there are clear differences in the propensity to donate blood across subjects of study (as documented in Table 1), and since we randomized treatments only within lectures, we purged the data in Table 3 of any course-specific effects. Specifically, we normalized the data by subtracting the corresponding 
course average from each observation. ${ }^{5}$

Table 3 presents these normalized data cut by treatment and by awareness. We first report descriptive statistics for actual blood donation behavior. Adjusted mean effects are shown in the upper half of Table 3. The effect of the active decision treatment on blood donations depends strongly on whether the subjects feel aware of the importance of donating blood or not. Subjects answering "no" to the awareness question show a clear increase in the tendency to donate blood in the strong $A D$ treatment relative to the weak $A D$ and the no $A D$ treatments. The last column of Table 3 calculates the difference between the strong $A D$ and no $A D$ treatments, and the associated standard error of the estimate. The difference is large relative to the baseline propensity to donate blood: The share of donors increases by 7.2 percentage points. The standard error for this difference is small, indicating a statistically significant treatment effect. On the other hand, subjects who responded with a "yes" to the awareness question were not more likely to donate blood if assigned to the strong $A D$. If "aware" people are explicitly asked to make a decision on whether or not to donate blood, they are less likely to donate blood than in the other treatments. As the last column shows, the share of donors is reduced by 2.9 percentage points in the strong $A D$ treatment relative to the no $A D$ treatment.

The lower half of Table 3 shows the survey responses to the invitation to donate blood in the strong and weak $A D$ treatments. Regardless of whether individuals felt aware of the importance of blood donations, the additional option ("I do not want to make a decision.") in the weak $A D$ seems to have reduced the share of individuals who said they would donate blood. This finding reflects the results on actual donation behavior. The last column in Table 3 calculates the difference between the strong and weak $A D$ conditions and the corresponding standard error. For both groups, regarding the stated willingness to donate, the standard error is large relative to the size of the effect.

\footnotetext{
${ }^{5}$ Without normalization, the shares of people donating blood in the groups exposed to the strong $A D$, weak $A D$, and no $A D$ are 11.3 percent, 8.1 percent, and 3.8 percent. On average, 8 percent of people not aware of the importance of donating blood and 7.6 percent of people aware donated blood. As we noted earlier, however, these numbers are difficult to interpret because our treatment is randomized only within a course, and the baseline donation rates of the various courses vary strongly.
} 


\section{Results}

\section{A. Blood Donations}

The data allow us to examine the effects of active decisions on actual blood donations, and on the stated willingness to donate blood expressed in the absence of costly consequences, that is, in a cheap talk situation. We estimate the impact of the experiment on blood donations (and stated preferences) using a linear probability model with robust standard errors (for a discussion see Moffitt (1999)). Where possible, we also adjust the standard errors for possible clustering on the course-treatment level (this being one reason for estimating linear probability models). As this reduces the effective degrees of freedom to the number of course-treatment clusters, we can apply this procedure only in specifications with fewer than 16 variables included.

The effects of the treatments on blood donations are reported in Tables 4 and 5. In these tables, the dependent variable is equal to one if an individual donates blood and zero otherwise. Thus, the coefficient of any variable in this regression can be directly interpreted as the change in the share of individuals donating blood resulting from a one-unit increase in the independent variable, holding the value of the other variables constant. We also present probit model estimates in the appendix.

We choose the third treatment, in which subjects were not required to fill out a decision sheet, as the reference category. We first present the overall effects of the two $A D$ conditions. Second, differential treatment effects are calculated, applying interaction terms between the experimental conditions and people's awareness of the importance of donating blood. Third, in four full-interaction models, treatment effects are reported separately for people who are not aware of the issue and for those who are aware of the issue.

For the full sample, we do not find any statistically significant differences between the three experimental conditions in how likely people are to donate blood. This holds whether a large set of personality characteristics is taken into account via control variables or not (see the first and second columns of Table 4). The additional control variables are jointly statistically significant predictors of blood donation behavior. Independently of the experimental conditions, on average, people who are aware of the issue seem less likely to donate blood than people who are not aware. ${ }^{6}$

\footnotetext{
${ }^{6}$ Note, however, that this coefficient is biased if there is an interaction effect between the experimental conditions and awareness.
} 
However, these overall findings hide significant variation in the effects of the experimental conditions. According to the differentiated hypothesis, the experimental conditions interact with people's reported awareness of the issue (see the third and fourth columns of Table 4). We find for people who are unaware of the importance of donating blood that a strong $A D$ substantially and statistically significantly increases the probability of donating blood. Relative to the condition with no $A D$, a strong $A D$ increases the probability by 8.2 percentage points. For the group of people unaware, the effect of a weak $A D$ on the probability of donating blood is also positive. However, our sample size does not allow us to estimate this effect accurately.

The estimated positive coefficient for the weak $A D$ is neither statistically significantly smaller than the coefficient for the strong $A D(p=0.2)$ nor statistically significantly larger than the level of donations of unaware people who were not exposed to an $A D(p=0.17)$. Thus, there is some weak evidence that the exposure to choice may mobilize pro-social behavior, independent of whether only a "yes" and a "no" option is available, or whether an option for "no decision" is also offered. This might also be explained by the possibility of leaving the decision sheet blank, which was available to all the individuals in both the strong and the weak $A D$ treatments. However, the standard error of the estimated coefficient for the weak $A D$ prevents us from drawing stronger conclusions. ${ }^{7}$

For the group of people aware of the issue, no differences in donation behavior across experimental conditions are found. We can reject the hypothesis that the two groups (aware versus not aware) respond to the treatments in the same way $(p<0.01)$. This is in line with our differentiated hypothesis that only individuals who have not made up their minds regarding blood donations are susceptible to the $A D$ manipulation.

Overall, the results for the experimental effects in Table 4 are robust to the inclusion of a large set of control variables. Moreover, the basic findings are also robust to a full interaction specification estimating separate regressions for people who are aware and those who are unaware of the importance of donating blood. The strong $A D$ intervention is estimated to increase the probability of

\footnotetext{
${ }^{7}$ While the estimation results from linear probability models and probit models provide qualitatively the same results for our data (see Tables A.1 and A.2), there is an exception for the weak $A D$ condition in the group of unaware people. Table A.2 in the appendix reports a statistically significant positive effect of the weak $A D$ treatment relative to the no $A D$ treatment. The slightly different results might be due to the sensitivity of coefficients estimated with probit when the average probability of the outcome variable is substantially different from 0.5 .
} 
donating blood by 8.7 percentage points relative to the no $A D$ condition (first column of Table 5). Even after adjusting the covariance matrix for clustering at the course-treatment level, our treatment effect is still highly statistically significant. $^{8}$ The effect is almost unchanged and still highly statistically significant when a large set of additional control variables is taken into account (second column of Table 5).

In the full interaction specification, the experimental interventions again matter much less for people who are aware of the issue and who have supposedly already made up their minds about donating blood. For people in the strong $A D$ condition, we actually find a slightly lower probability (-2.4 percentage points) of donating blood - although not statistically significant - than in the control condition (third column of Table 5). The finding is very similar when we add more controls in the fourth column of Table 5 .

We examine three alternative interpretations of our results: The first one is that the findings reflect experimentation, and that our measure for awareness is picking up a preference for finding out about the process of donating blood (How much does it hurt? Do I feel dizzy afterwards?). Remember, we argue that our treatments uncover latent social preferences, and not the process of donating itself. It is, thus, important to distinguish between the two explanations. At the outset, one has to keep in mind that we already control for past blood donations in Tables 4 and 5. Hence, any higher propensity to donate blood in order to "experiment" by former non-donors is absorbed in the equation and is uncorrelated with our treatments. However, as we argued before, the active decision treatment may have offered a form of mental commitment and thus a better technology for learning about blood donations. This raises the possibility that people who had never donated blood before may have been encouraged to "experiment" more in the strong $A D$ treatment than in the weak $A D$ and no $A D$ treatments.

We examine this alternative explanation by exploiting the fact that there are still subjects (16 percent) who donated blood in the past but answer that they are not sufficiently aware of the importance of blood donations. Although this group is relatively small (70 individuals), we can examine whether this group still responds to our treatments as we hypothesized earlier. The results are displayed

\footnotetext{
${ }^{8}$ See the standard errors in brackets in Table 4 . In order to calculate these standard errors, we de-mean the data on the course level. This is algebraically equivalent to including dummy variables in the regression, but it does not reduce the degrees of freedom (as we are not calculating the covariance matrix for the course effects).
} 
in Table 6, where we estimate the treatment effects for this group as the main effect, and interaction terms for the group of subjects who had never donated blood before. We find little evidence that our strong $A D$ treatment impacts only the behavior of subjects who had never donated blood before. Individuals who donated blood before, but still do not feel sufficiently aware of the importance of blood donations, are more likely to donate blood in the treatment group: the point estimate is virtually unchanged relative to the baseline results in Table 5 , and still statistically significant. The interaction term shows that, if anything, the strong $A D$ condition affects donors with previous experience more strongly, though we lack the precision to make strong statements about this. But there is clearly no evidence that the effect is weaker for donors who donated before. Column 2 in Table 6 shows that for people who state that they are aware of the importance of blood donation, there is also no response to the treatment when they have never donated blood before. This, again, lends little support to the alternative hypothesis that the active decision treatment encouraged subjects to try to learn about blood donations in general. Our findings indicate that people respond to the treatment when they feel that they are unaware of the importance of blood donations, rather than unfamiliar with the act of donating blood per se.

The second alternative explanation is that our treatment may have facilitated blood donations of individuals with a self-control problem due to presentbiased preferences (see, for example, O'Donoghue and Rabin (1999)). Presentbiased preferences have been shown to have strong effects on behavior in similar realms (Della Vigna and Malmendier, 2006). Offering our treatment group a mental commitment mechanism may have facilitated blood donations of individuals with present-biased preferences. Because of this present bias, those same individuals may have procrastinated thinking about the importance of blood donations, thus generating an artificial correlation between our awareness variable and the treatment. To address this issue, we asked the respondents in our survey a simple question to measure impatience: Would they prefer CHF 50 right now or CHF 60 two months from now? We use the responses to this question as a proxy for impatience. The individuals split roughly 50:50 on the two options. In the third and fourth columns of Table 6, we interact the treatment effects with impatience. If our treatments act through mitigating self-control problems, we would expect to see a larger treatment effect on individuals who report impatience in the survey. However, we find no difference between the two groups. Column 3 shows a large effect of the strong $A D$ treatment on donations 
of individuals who are unaware of the importance of blood donations and report that they are patient. There is no difference in the treatment effect for the group that reports being impatient $(p=0.31)$. Further, commitment opportunities for individuals with self-control problems are the same for individuals who feel sufficiently informed about blood donations. Yet, we find no evidence in the fourth column that impatient individuals are more likely to donate blood when exposed to a strong $A D$ treatment. Overall, these results lend little support to the time-preferences explanation.

The third alternative explanation questions the measure of awareness as an indicator of the degree of preference formation. It might be speculated that the measure rather picks up differences in personality and, in particular, how conscientious they are (one of the Big-Five personality characteristics, see Gosling, Rentfrow, and Swann (2003)). Conscientious individuals may be more likely to have thought about the importance of blood donations, and at the same time, feel more obliged in the $A D$ treatments to donate blood. This could potentially give rise to a spurious association between whether or not individuals state that they are sufficiently informed about the importance of blood donation and our treatment. Again, we test this alternative explanation by interacting the treatments with the conscientiousness score obtained from our survey. The traits are measured on a scale from 1 to 7 , with 1 indicating the lowest, and 7 the highest degree of conscientiousness. We split the sample at the median (5.5 in this case). Columns 5 and 6 in Table 6 display the results. We find no differences in treatment effects with respect to conscientiousness in either the sample of people who report being sufficiently aware or in the other sample. The point estimates on the interaction term are small in magnitude (less than two percentage points in either case), and the $p$-values are nowhere near conventional levels of statistical significance. Thus, differences in conscientiousness do not explain our differential treatment effects for the aware and unaware groups.

In sum, the $A D$ intervention does not generally increase the probability of donating blood. Rather, and in line with the differentiated hypothesis, the treatment effect depends on whether people had already formed preferences about donating blood. If people who do not feel sufficiently aware of the issue are approached, active decisions affect pro-social behavior even when high immediate costs are involved. 


\section{B. Stated Preferences}

Table 7 summarizes the results for people's stated willingness to donate blood. We present only the results for the full interaction specification. Because people in the third experimental condition did not state their preferences beforehand, it is possible to compare only the strong and weak $A D$ conditions.

We find that the strong $A D$ treatment has a positive effect on the expressed willingness to donate, in accordance with the basic hypothesis. There is a difference of 4.5 percentage points in the treatment effect between people who are unaware and those who are aware of the importance of donating blood, however imprecisely estimated (first and third column of Table 7). The probability of stating a willingness to donate blood increases by 7.2 percentage points for people who are not aware of the issue, but this result is only borderline significant. In contrast, there is an increase of only 2.7 percentage points (not statistically significant) for people who are aware of the issue. This difference in the treatment effects between the two groups becomes somewhat more pronounced when a large set of additional control variables from the survey is included (second and fourth column of Table 7).

In sum, we find that the implemented strong $A D$ treatment has a significant positive effect over and above the weak $A D$ treatment on stated preferences and on the contribution of individuals indicating relative unawareness of the topic. In contrast, no significant difference is observed for those who are aware of the issue. Thus, we do not observe a general positive effect. The results instead show an asymmetry in the effects of the experimental conditions, depending on the formation of preferences as formulated in the differentiated hypothesis.

\section{Concluding Remarks}

We examine whether an active-decision framework affects perception and cognition processes to the extent that pro-social behavior is evoked. People are asked in an active decision to either consent to or dissent from a request in an otherwise unrestrained choice situation; that is, subjects are de facto confronted

with the same behavioral options as in a situation where no active decision is involved. Behavioral consequences of active decisions arise if by asking for an explicit statement: (i) cognitive processes are stimulated in which a more indepth examination of the request's content takes place than in the case of not requesting an explicit answer, and (ii) the expressed choice is understood as commitment. 
The effect of active decisions on pro-social behavior is studied in a large-scale field experiment in blood donations. Almost 2,000 people were invited in a nonbinding manner to donate blood at a blood drive, which was taking place the week after the survey intervention. In a newly designed questionnaire, people answered various topic and attitude-related questions. Individuals assigned to the strong $A D$ condition were explicitly asked at the end of the questionnaire whether they were willing to donate blood in the upcoming blood drive or not. In the second group, with a weak $A D$, individuals had the additional option of checking a box, stating that they did not want to make a decision. In the third group, no explicit request was formulated in the questionnaire.

We find that, for people without well-formed preferences on blood donation, a strong active decision intervention increases their likelihood of donating blood, despite the high immediate opportunity costs. For people who report being aware of the blood donation issue, we find a small, although not statistically significant, negative effect.

The strong $A D$ also affects people's stated willingness to donate blood relative to a weak $A D$ intervention if they have no fully formed preferences about the issue. In the field of blood donation, the effect on the preference statement is, of course, less relevant. However, it indicates that an $A D$ might be effective in other social areas, like post-mortem organ donation or individual saving behavior, where a statement with low immediate costs puts people on a donor list or in a savings plan. This might be seen as an ethically attractive alternative to presumed consent.

Our results differ from those in research on mere measurement effects (Morwitz, Johnson, and Schmittlein, 1993) where, for example, asking people whether they intend to buy "a car" is shown to increase their probability of actually buying one. An $A D$ intervention elicits pro-social behavior oriented towards a specific activity. The results further indicate that whether or not people act pro-socially is not given, but is rather context- and issue-specific.

Active decisions are potentially a procedural innovation to develop the "latent social asset" in society. It is, however, important to learn when active decisions are perceived as supportive (rather than controlling) and work to build up pro-social preferences. One question might be, for example, how often an active decision framework can be applied when its effect varies with subject awareness. However, a simple intervention might be enough to overcome the stickiness of a low-contribution status quo for some issues like post-mortem organ donation. 


\section{References}

Choi, James J., David Laibson, Brigitte C. Madrian, and Andrew Metrick. 2004. "Optimal Defaults and Active Decisions." Unpublished, Mimeo, Harvard University.

Cioffi, Delia, and Randy Garner. 1996. "On Doing the Decision: Effects of Active Versus Passive Choice on Commitment and Self-perception." Personality and Social Psychology Bulletin 22:133-147.

Della Vigna, Stefano, and Ulrike Malmendier. 2006. "Paying Not to Go to the Gym." American Economic Review 96:694-719.

Frey, Bruno S. 1997. Not Just for the Money: An Economic Theory of Personal Motivation. Cheltenham: Edward Elgar Publishing.

Gosling, Samuel D., Peter J. Rentfrow, and William B. Swann. 2003. "A Very Brief Measure of the Big-Five Personality Domains." Journal of Research in Personality 37:504-528.

Kahneman, Daniel, Ilana Ritov, and David Schkade. 1999. "Economic Preferences or Attitude Expressions? An Analysis of Dollar Responses to Public Issues." Journal of Risk and Uncertainty 19:203-235.

Lemmens, K. P. H., C. Abraham, T. Hoekstra, R. A. C. Ruiter, W. L. A. M. De Kort, J. Burg, and H. P. Schaalma. 2005. "Why Don't Young People Volunteer to Give Blood? An Investigation of the Correlates of Donation Intentions among Young Nondonors." Transfusion 45:945-955.

Moffitt, Robert A. 1999. "New Developments in Econometric Methods for Labor Market Analysis." In Orley Ashenfelter and David Card, eds. Handbook of Labor Economics, Vol. 3A. Amsterdam: Elsevier, pp. 1367-1397.

Morwitz, Vicki G., Eric Johnson, and David Schmittlein. 1993. "Does Measuring Intent Change Behavior?" Journal of Consumer Research 20:46-61.

O'Donoghue, Ted, and Matthew Rabin. 1999. "Doing it Now or Later." American Economic Review 89:103-124.

Titmuss, Richard Morris. 1972. The Gift Relationship: From Human Blood to Social Policy. New York: Vintage Books. 
Table 1: Descriptive Statistics

\begin{tabular}{lcccc}
\hline Course & $\begin{array}{c}\text { Percent stating } \\
\text { willingness } \\
\text { to donate blood }^{a}\end{array}$ & $\begin{array}{c}\text { Percent } \\
\text { donating }^{b}\end{array}$ & $\begin{array}{c}\text { Percent aware of } \\
\text { importance of } \\
\text { donating blood }\end{array}$ & $N$ \\
\hline Medical school (first year) & $29.7 \%$ & $24.0 \%$ & $72.4 \%$ & 246 \\
Medical school (second year) & $16.8 \%$ & $11.0 \%$ & $88.9 \%$ & 171 \\
Biology (first year) & $20.2 \%$ & $8.9 \%$ & $70.1 \%$ & 157 \\
Economics (first year) & $8.6 \%$ & $5.2 \%$ & $64.4 \%$ & 399 \\
Economics (second year) & $4.8 \%$ & $2.0 \%$ & $74.6 \%$ & 354 \\
Journalism (first year) & $7.9 \%$ & $3.9 \%$ & $57.9 \%$ & 178 \\
Law (first year) & $8.9 \%$ & $3.9 \%$ & $64.3 \%$ & 333 \\
Total & $14.0 \%$ & $7.6 \%$ & $69.5 \%$ & 1,838 \\
\hline
\end{tabular}

Notes: ${ }^{a}$ Calculations are based on subjects in the weak $A D$ and strong $A D$ conditions $(N=1302) .{ }^{b}$ Calculations are based on the full sample. 


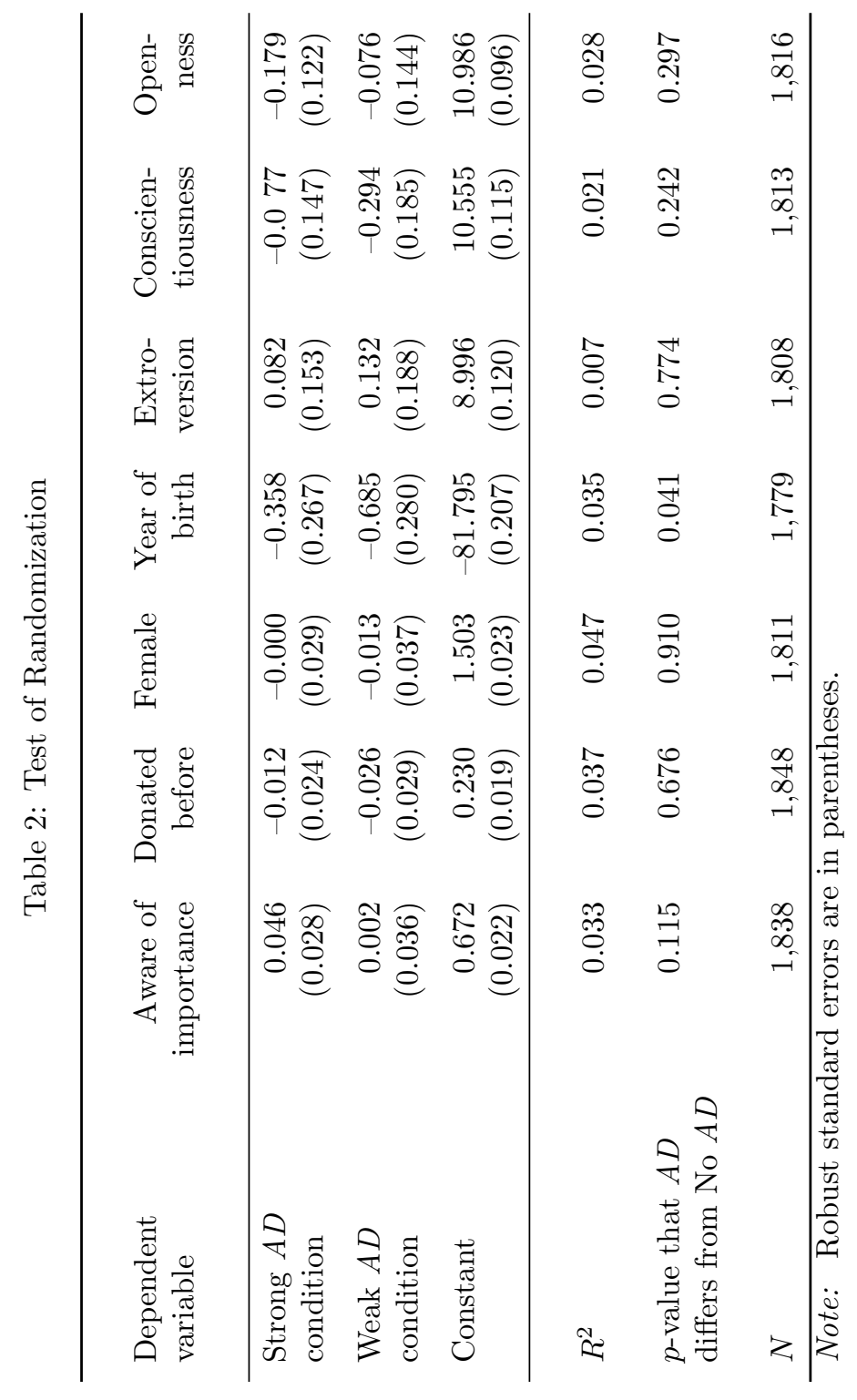


Table 3: The Experimental Outcomes

\begin{tabular}{lcccc}
\hline & \multicolumn{4}{c}{ Fraction donating blood, course mean subtracted } \\
\cline { 2 - 5 } & & & & Difference \\
Importance of & & & & \\
donating blood & Strong $A D$ & Weak $A D$ & No $A D$ & Strong $A D-$ No $A D$ \\
Not aware & 0.040 & 0.010 & -0.032 & 0.072 \\
$N$ & 249 & 134 & 177 & $(0.021)$ \\
Aware & -0.015 & 0.001 & 0.013 & -0.029 \\
$N$ & 654 & 265 & 359 & $(0.015)$ \\
& & & & \\
\hline
\end{tabular}

Fraction stating willingness to donate, course mean subtracted

$\begin{array}{lcccc}\begin{array}{l}\text { Importance of } \\ \text { donating blood }\end{array} & \text { Strong } A D & \text { Weak } A D & \text { No } A D & \begin{array}{c}\text { Difference } \\ \text { Strong AD - Weak } A D\end{array} \\ \text { Not aware } & 0.055 & -0.004 & \text { n/a } & 0.059 \\ N & 249 & 134 & & (0.036) \\ & & & & 0.023 \\ \text { Aware } & -0.007 & -0.030 & \text { n/a } & (0.024) \\ N & 654 & 265 & & \\ \end{array}$

Note: Standard error of estimates in parentheses. 
Table 4: The Effect of Active Decisions on Actual Blood Donation: Overall and Single Interaction Results

Dependent variable: donated blood $(=1)$

Linear probability models

\begin{tabular}{|c|c|c|c|c|}
\hline & (1) & $(2)$ & $(3)$ & (4) \\
\hline Strong $A D$ condition & $\begin{array}{r}0.010 \\
(0.013) \\
{[0.013]}\end{array}$ & $\begin{array}{r}0.009 \\
(0.013)\end{array}$ & & \\
\hline Weak $A D$ condition & $\begin{array}{r}0.009 \\
(0.019) \\
{[0.016]}\end{array}$ & $\begin{array}{r}0.007 \\
(0.020)\end{array}$ & & \\
\hline $\begin{array}{l}\text { Aware of importance } \\
\text { of donating blood }\end{array}$ & $\begin{array}{r}-0.018 \\
(0.015) \\
{[0.019]}\end{array}$ & $\begin{array}{l}-0.019 \\
(0.015)\end{array}$ & $\begin{array}{l}0.040^{* * *} \\
(0.015) \\
{[0.019]}\end{array}$ & $\begin{array}{l}0.035^{* *} \\
(0.015)\end{array}$ \\
\hline Aware $\times$ strong $A D$ & & & $\begin{array}{c}-0.021 \\
(0.016) \\
{[0.016]}\end{array}$ & $\begin{array}{l}-0.020 \\
(0.016)\end{array}$ \\
\hline Aware $\times$ weak $A D$ & & & $\begin{array}{l}-0.005 \\
(0.025) \\
{[0.023]}\end{array}$ & $\begin{array}{l}-0.005 \\
(0.025)\end{array}$ \\
\hline Not aware $\times$ strong $A D$ & & & $\begin{array}{l}0.082^{* * *} \\
(0.024) \\
{[0.028]}\end{array}$ & $\begin{array}{l}0.078^{* * *} \\
(0.024)\end{array}$ \\
\hline Not aware $\times$ weak $A D$ & & & $\begin{array}{r}0.038 \\
(0.028) \\
{[0.019]}\end{array}$ & $\begin{array}{r}0.035 \\
(0.028)\end{array}$ \\
\hline Age, gender & Yes & Yes & Yes & Yes \\
\hline Course fixed effects & Yes & Yes & Yes & Yes \\
\hline Pro-social motivation $^{a}$ & No & Yes & No & Yes \\
\hline Life goals ${ }^{b}$ & No & Yes & No & Yes \\
\hline Personality $^{c}$ & No & Yes & No & Yes \\
\hline Past behavior $^{d}$ & No & Yes & No & Yes \\
\hline $\begin{array}{l}\text { Behavior of relatives } \\
\text { and friends }{ }^{e}\end{array}$ & No & Yes & No & Yes \\
\hline$R^{2}$ & 0.076 & 0.094 & 0.082 & 0.099 \\
\hline$N$ & 1688 & 1688 & 1688 & 1688 \\
\hline
\end{tabular}

Notes: Robust standard errors are in parentheses. Standard errors adjusted for clustering on course $\times$ treatments are in brackets. No $A D$ is the reference category. The control variables are defined as follows: ${ }^{a}$ pro-social motivations along 4 dimensions reported on 7 -point scales; ${ }^{b}$ intrinsic and extrinsic lifegoals along 6 dimensions on 7 -point scales; ${ }^{c}$ ten personality characteristics each representing an opposite pole of the Big-Five personality dimensions (7-point scales); ${ }^{d}$ indicator of whether an individual made a blood donation in the past; $e$ past blood donation behavior of relatives and friends. Significance levels: * $.05<p<.1,{ }^{* *} .01<p<.05,{ }^{* * *} p<.01$, two-tailed test. 
Table 5: The Effect of Active Decisions on Actual Blood Donation: Full Interactions Results

Dependent variable: donated blood $(=1)$

Linear probability models

\begin{tabular}{|c|c|c|c|c|}
\hline \multirow[b]{2}{*}{ Strong $A D$ condition } & \multicolumn{2}{|c|}{$\begin{array}{c}\text { Not aware of } \\
\text { importance of } \\
\text { donating blood }\end{array}$} & \multicolumn{2}{|c|}{$\begin{array}{c}\text { Aware of } \\
\text { importance of } \\
\text { donating blood }\end{array}$} \\
\hline & $\begin{array}{l}0.087^{* * *} \\
(0.025)\end{array}$ & $\begin{array}{l}0.081^{* * *} \\
(0.024)\end{array}$ & $\begin{array}{r}-0.024 \\
(0.016)\end{array}$ & $\begin{array}{l}-0.023 \\
(0.016)\end{array}$ \\
\hline Weak $A D$ condition & $\begin{array}{r}0.045 \\
(0.030)\end{array}$ & $\begin{array}{r}0.034 \\
(0.031)\end{array}$ & $\begin{array}{l}-0.006 \\
(0.025)\end{array}$ & $\begin{array}{l}-0.005 \\
(0.025)\end{array}$ \\
\hline Age, gender & Yes & Yes & Yes & Yes \\
\hline Course fixed effects & Yes & Yes & Yes & Yes \\
\hline Pro-social motivation $^{a}$ & No & Yes & No & Yes \\
\hline Life goals ${ }^{b}$ & No & Yes & No & Yes \\
\hline Personality $^{c}$ & No & Yes & No & Yes \\
\hline Past behavior $^{d}$ & No & Yes & No & Yes \\
\hline $\begin{array}{l}\text { Behavior of relatives } \\
\text { and friends }\end{array}$ & No & Yes & No & Yes \\
\hline$R^{2}$ & 0.118 & 0.164 & 0.070 & 0.085 \\
\hline$N$ & 496 & 496 & 1,192 & 1,192 \\
\hline
\end{tabular}

Notes: Robust standard errors are in parentheses. No $A D$ is the reference category. The control variables are defined as follows: ${ }^{a}$ pro-social motivations along 4 dimensions reported on 7 -point scales; ${ }^{b}$ intrinsic and extrinsic lifegoals along 6 dimensions on 7 -point scales; ${ }^{c}$ ten personality characteristics each representing an opposite pole of the Big-Five personality dimensions (7point-scales); ${ }^{d}$ indicator of whether an individual made a blood donation in the past; ${ }^{e}$ past blood donation behavior of relatives and friends. Significance levels: ${ }^{*} .05<p<.1,{ }^{* *} .01<p<.05,{ }^{* * *} p<.01$, two-tailed test. 


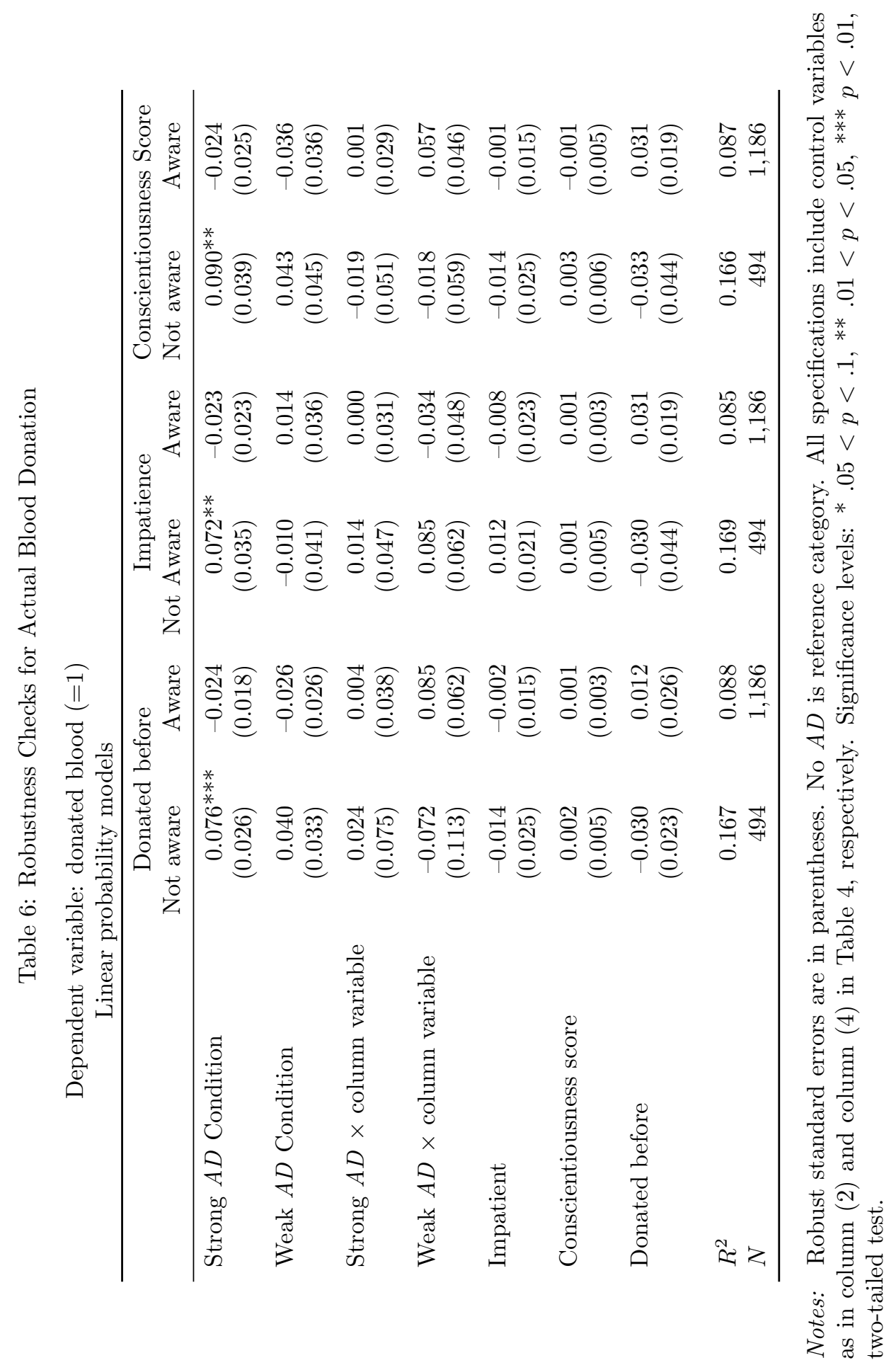


Table 7: The Effect of Active Decisions on the Stated Willingness to Donate Blood

Dependent variable: indicated willingness to donate blood $(=1)$ Linear probability models

\begin{tabular}{|c|c|c|c|c|}
\hline \multirow[b]{2}{*}{ Strong AD Condition } & \multicolumn{2}{|c|}{$\begin{array}{l}\text { Not aware of } \\
\text { importance of } \\
\text { donating blood }\end{array}$} & \multicolumn{2}{|c|}{$\begin{array}{c}\text { Aware of } \\
\text { importance of } \\
\text { donating blood }\end{array}$} \\
\hline & $\begin{array}{c}0.072^{*} \\
(0.043)\end{array}$ & $\begin{array}{c}0.086^{*} \\
(0.044)\end{array}$ & $\begin{array}{r}0.027 \\
(0.027)\end{array}$ & $\begin{array}{r}0.033 \\
(0.027)\end{array}$ \\
\hline Age, gender & Yes & Yes & Yes & Yes \\
\hline Course fixed effects & Yes & Yes & Yes & Yes \\
\hline Pro-social motivation $^{a}$ & No & Yes & No & Yes \\
\hline Life goals ${ }^{b}$ & No & Yes & No & Yes \\
\hline Personality $^{c}$ & No & Yes & No & Yes \\
\hline Past behavior $^{d}$ & No & Yes & No & Yes \\
\hline $\begin{array}{l}\text { Behavior of relatives } \\
\text { and friends }{ }^{e}\end{array}$ & No & Yes & No & Yes \\
\hline$R^{2}$ & 0.113 & 0.172 & 0.079 & 0.129 \\
\hline$N$ & 339 & 339 & 855 & 855 \\
\hline
\end{tabular}

Notes: Robust standard errors are in parentheses. No $A D$ is the reference category. The control variables are defined as follows: ${ }^{a}$ pro-social motivations along 4 dimensions reported on 7 -point scales; ${ }^{b}$ intrinsic and extrinsic life-goals along 6 dimensions on 7 -point scales; ${ }^{c}$ ten personality characteristics each representing an opposite pole of the Big-Five personality dimensions (7-point scales); ${ }^{d}$ indicates whether an individual made a blood donation in the past; ${ }^{e}$ past blood donation behavior of relatives and friends. Significance levels: ${ }^{*} .05<p<.1,{ }^{* *} .01<p<.05,{ }^{* * *} p<.01$, two-tailed test. 
Table 8: Number of Observations by Course and Treatment

\begin{tabular}{lccc}
\hline & Strong $A D$ & Weak $A D$ & No $A D$ \\
\cline { 2 - 4 } Medical school (first year) & 130 & 116 & \\
Medical school (second year) & 124 & 49 & \\
Biology (first year) & 94 & & 63 \\
Economics (first year) & 169 & 88 & 147 \\
Economics (second year) 2 & 147 & & 209 \\
Journalism & 118 & 60 & \\
Law & 127 & 87 & 120 \\
Total & 909 & 400 & 539 \\
\hline
\end{tabular}


Table A.1: The Effect of Active Decisions on Actual Blood Donation: Overall and Single Interaction Results

Dependent variable: donated blood $(=1)$

Marginal effects from ML probit estimates

\begin{tabular}{|c|c|c|c|c|}
\hline & (1) & (2) & (3) & (4) \\
\hline Strong $A D$ condition & $\begin{array}{r}0.014 \\
(0.017)\end{array}$ & $\begin{array}{r}0.012 \\
(0.016)\end{array}$ & & \\
\hline Weak $A D$ condition & $\begin{array}{r}0.017 \\
(0.022)\end{array}$ & $\begin{array}{r}0.013 \\
(0.020)\end{array}$ & & \\
\hline $\begin{array}{l}\text { Aware of importance } \\
\text { of donating blood }\end{array}$ & $\begin{array}{l}-0.015 \\
(0.014)\end{array}$ & $\begin{array}{l}-0.013 \\
(0.013)\end{array}$ & $\begin{array}{l}0.059^{* *} \\
(0.024)\end{array}$ & $\begin{array}{l}0.056^{* *} \\
(0.022)\end{array}$ \\
\hline Aware $\times$ strong $A D$ & & & $\begin{array}{l}-0.017 \\
(0.017)\end{array}$ & $\begin{array}{l}-0.015 \\
(0.016)\end{array}$ \\
\hline Aware $\times$ weak $A D$ & & & $\begin{array}{l}-0.003 \\
(0.021)\end{array}$ & $\begin{array}{l}-0.005 \\
(0.019)\end{array}$ \\
\hline Not aware $\times$ strong $A D$ & & & $\begin{array}{l}0.156^{* *} \\
(0.077)\end{array}$ & $\begin{array}{c}0.153^{*} \\
(0.080)\end{array}$ \\
\hline Not aware $\times$ weak $A D$ & & & $\begin{array}{r}0.107 \\
(0.076)\end{array}$ & $\begin{array}{r}0.104 \\
(0.078)\end{array}$ \\
\hline Age, gender & Yes & Yes & Yes & Yes \\
\hline Course fixed effects & Yes & Yes & Yes & Yes \\
\hline Pro-social motivation $^{a}$ & No & Yes & No & Yes \\
\hline Life goals ${ }^{b}$ & No & Yes & No & Yes \\
\hline Personality $^{c}$ & No & Yes & No & Yes \\
\hline Past behavior $^{d}$ & No & Yes & No & Yes \\
\hline $\begin{array}{l}\text { Behavior of relatives } \\
\text { and friends }{ }^{e}\end{array}$ & No & Yes & No & Yes \\
\hline Pseudo- $R^{2}$ & 0.076 & 0.094 & 0.082 & 0.099 \\
\hline$N$ & 1,688 & 1,688 & 1,688 & 1,688 \\
\hline
\end{tabular}

Notes: Marginal effects of binary variables are evaluated calculating the discrete differences in the c.d.f., averaged over individuals. Standard errors are in parentheses. Standard errors adjusted for clustering on course $\times$ treatments are in brackets. No $A D$ is the reference category. The control variables are defined as follows: ${ }^{a}$ pro-social motivations along 4 dimensions reported on 7 point scales; ${ }^{b}$ intrinsic and extrinsic life-goals along 6 dimensions on 7 -point scales; ${ }^{c}$ ten personality characteristics each representing an opposite pole of the Big-Five personality dimensions (7-point scales); ${ }^{d}$ indicator of whether an individual made a blood donation in the past; ${ }^{e}$ past blood donation behavior of relatives and friends. Significance levels: ${ }^{*} .05<p<.1{ }^{* *} .01<p<.05$, *** $p<.01$, two-tailed test. 
Table A.2: The Effect of Active Decisions on Actual Blood Donation: Full Interactions Results

Dependent variable: donated blood $(=1)$

Marginal effects from ML probit estimates

\begin{tabular}{|c|c|c|c|c|}
\hline \multirow[b]{2}{*}{ Strong $A D$ condition } & \multicolumn{2}{|c|}{$\begin{array}{l}\text { Not aware of } \\
\text { importance of } \\
\text { donating blood }\end{array}$} & \multicolumn{2}{|c|}{$\begin{array}{c}\text { Aware of } \\
\text { importance of } \\
\text { donating blood }\end{array}$} \\
\hline & $\begin{array}{l}0.116^{* * *} \\
(0.039)\end{array}$ & $\begin{array}{l}0.091^{* * *} \\
(0.035)\end{array}$ & $\begin{array}{l}-0.026 \\
(0.020)\end{array}$ & $\begin{array}{l}-0.024 \\
(0.019)\end{array}$ \\
\hline Weak $A D$ condition & $\begin{array}{c}0.110^{*} \\
(0.062)\end{array}$ & $\begin{array}{c}0.095^{*} \\
(0.056)\end{array}$ & $\begin{array}{l}-0.012 \\
(0.021)\end{array}$ & $\begin{array}{l}-0.012 \\
(0.020)\end{array}$ \\
\hline Age, gender & Yes & Yes & Yes & Yes \\
\hline Course fixed effects & Yes & Yes & Yes & Yes \\
\hline Pro-social motivation $^{a}$ & No & Yes & No & Yes \\
\hline Life goals ${ }^{b}$ & No & Yes & No & Yes \\
\hline Personality $^{c}$ & No & Yes & No & Yes \\
\hline Past behavior $^{d}$ & No & Yes & No & Yes \\
\hline $\begin{array}{l}\text { Behavior of relatives } \\
\text { and friends }{ }^{e}\end{array}$ & No & Yes & No & Yes \\
\hline Pseudo- $R^{2}$ & 0.118 & 0.164 & 0.070 & 0.085 \\
\hline$N$ & 496 & 496 & 1,192 & 1,192 \\
\hline
\end{tabular}

Notes: Marginal effects of binary variables are evaluated calculating the disrete differences in the c.d.f., averaged over individuals. Standard errors are in parentheses. No $A D$ is the reference category. The control variables are defined as follows: ${ }^{a}$ pro-social motivations along 4 dimensions reported on 7 -point scales; ${ }^{b}$ intrinsic and extrinsic life-goals along 6 dimensions on 7 -point scales; ${ }^{c}$ ten personality characteristics each representing an opposite pole of the Big-Five personality dimensions (7-point-scales); ${ }^{d}$ indicator of whether an individual made a blood donation in the past; ${ }^{e}$ past blood donation behavior of relatives and friends. Significance levels: ${ }^{*} .05<p<.1,{ }^{* *} .01<p<.05,{ }^{* * *} p<.01$, two-tailed test. 